\title{
Políticas linguísticas familiares em contexto de línguas minoritárias
}

\author{
Isabella Mozzillo ${ }^{1}$ \\ Programa de pós-graduação em Letras, Universidade Federal de Pelotas, Pelotas, RS, Brasil \\ Karen Pupp Spinassé2 \\ Programa de pós-graduação em Letras, Universidade Federal do Rio Grande do Sul, Porto Alegre, RS, Brasil
}

Resumo: Neste artigo, apresentaremos resultados de uma pesquisa desenvolvida com indivíduos bilíngues que falam uma língua considerada "minoritária" como uma de suas línguas maternas. Os participantes da pesquisa responderam a um questionário ou a uma entrevista sobre suas práticas linguísticas no âmbito do lar, que visavam a coletar dados sobre as políticas linguísticas familiares (KING; FOGLE; LOGANTERRY, 2008; SPOLSKY, 2012) estabelecidas nesse contexto e as ideologias que regem essas práticas. Partimos do pressuposto de que as ideologias linguísticas (SPOLSKY, 2004; 2012) desses falantes poderiam estar sob influência de mitos e concepções que conferem à língua minoritária um status negativo, cercado de preconceito linguístico. Apresentaremos, aqui, resultados referentes a cinco participantes da pesquisa, falantes de línguas minoritárias, que foram analisados de forma qualitativa, para desvelar suas ideologias linguísticas.

Palavras-chave: Políticas linguísticas familiares; Línguas minoritárias; Preconceito linguístico.

Title: Family language policies in context of minority languages

Abstract: In this paper, we present the results of a research carried out with bilingual individuals who speak a so called "minority" language as one of their mother tongues. The research participants answered a questionnaire or an interview about their linguistic practices at home, which aimed to collect data on the family linguistic policies (KING; FOGLE; LOGANTERRY, 2008; SPOLSKY, 2012) established in this context and the ideologies that govern these practices. We assume that the linguistic ideologies (SPOLSKY, 2004; 2012) of these speakers could be under influence of myths and concepts that give the minority language a negative status, surrounded by linguistic prejudice. We present here results referring to five participants of the research, speakers of minority languages, which were analyzed in a qualitative way to unveil their linguistic ideologies.

Keywords: Family language policies; Minority languages; Linguistic prejudice.

1 Doutora em Letras (PUCRS), UFPel. Orcid: https://orcid.org/0000-0001-8445-9174. E-mail: isabellamozzillo@gmail.com.

${ }^{2}$ Doutora em Linguística Aplicada (Technische Universität Berlin), UFRGS. Orcid: https://orcid.org/0000-00021379-8387. E-mail: spinasse@ufrgs.br. 


\section{Introdução}

O contexto de línguas minoritárias - ou línguas minorizadas - é, muitas vezes, cercado de preconceito linguístico. Existem diferentes tipos de línguas minoritárias (vide ALTENHOFEN; MORELLO, 2013, p. 20) e, analisando suas características, podemos ver que sua classificação como tal, muitas vezes, não é motivada por uma questão numérica, mas sim por questões relacionadas ao prestígio.

Existem aquelas línguas que, apesar de serem consideradas "minoritárias", têm mais reconhecimento oficial, sendo, portanto, respaldadas por políticas públicas. Esse é o caso da Língua Brasileira de Sinais, tida como língua minoritária por ser utilizada por um grupo restrito de pessoas, mas tendo o seu uso oficialmente legalizado pela lei $n^{0} 10.436$ de $2002^{3}$ e gozando, por decreto, de presença obrigatória em espaços oficiais. ${ }^{4}$ Existem línguas minoritárias, também faladas por um número restrito de indivíduos, as quais gozam de prestígio, como é o caso de algumas línguas mundialmente valorizadas e majoritárias em outros contextos. Uma família de americanos falantes de inglês no Brasil, por exemplo, costuma receber atitudes positivas por parte dos outros membros da sociedade, já que falar inglês é visto, no senso comum, como algo positivo. Contudo, existem aquelas línguas minoritárias que, independentemente de terem ou não um elevado número de falantes, não são valorizadas, devido ao status que thes é conferido. Geralmente, elas sofrem de alguma carga de preconceito, de cunho histórico ou social, que as marcam com certo desprestígio (vide ALTENHOFEN, 2004; HILGEMANN, 2004; SCHNEIDER, 2007; PUPP SPINASSÉ, 2016). Esse é o caso das línguas de imigração e, em alguns casos, das línguas de herança. ${ }^{5}$

Neste artigo, apresentaremos alguns resultados de uma pesquisa que visou a obter dados sobre as políticas linguísticas familiares (KING; FOGLE; LOGANTERRY, 2008; SPOLSKY, 2012) praticadas por indivíduos bilíngues, coletando dados sobre suas concepções linguísticas e sobre a organização linguística que eles desenvolvem em seus lares, com sua família. Como recorte para o presente artigo, analisaremos os casos que envolveram especificamente línguas de imigração e línguas de herança, com o intuito de avaliar que ideologias linguísticas (SPOLSKY, 2004; 2012) subjazem os seus falantes e que concepções esses falantes de uma língua minoritária têm sobre sua própria língua.

Para tanto, o artigo será dividido em quatro seções: primeiramente, faremos uma breve explanação dos pressupostos teóricos que baseiam nossa pesquisa; em seguida, contextualizaremos a pesquisa metodologicamente, elucidando também os objetivos da mesma; na terceira seção, traremos os dados empíricos coletados nas entrevistas e nos questionários que foram mobilizados, apresentando os discursos dos falantes em relação à

\footnotetext{
${ }^{3}$ Disponível em: https://www.libras.com.br/lei-10436-de-2002. Acesso em: 16 jul. 2020.

${ }^{4}$ Disponível em: http://www.planalto.gov.br/ccivil 03/ Ato2015-2018/2018/Decreto/D9656.htm. Acesso em: 16 jul. 2020. É importante, contudo, fazer a ressalva de que não necessariamente a LIBRAS alcançou com essas leis e decretos o status que merece, uma vez que, como se pode ler nos documentos, não é língua oficial, pertencendo, portanto, ao rol de línguas minoritárias.

${ }^{5}$ As definições dos termos serão dadas na próxima seção deste artigo.
} 
sua língua materna minoritária, acompanhado de um panorama das respostas; nas conclusões, por fim, faremos uma análise geral dos dados apresentados, tecendo nossas considerações finais.

\title{
Pressupostos teóricos
}

Como mencionado na Introdução, trataremos, neste artigo, de cinco casos, coletados, no âmbito de nosso projeto de pesquisa, através de questionário ou entrevista, em que falantes de uma língua minoritária (de imigração ou de herança) relatam sobre suas práticas linguísticas familiares e, consequentemente, sua relação com essa língua materna. É importante, portanto, elucidar, neste momento, o que entendemos neste artigo por Língua Materna, Língua de Imigração e Língua de Herança e as delimitações que enxergamos entre estes termos.

Falantes de línguas minoritárias geralmente aprendem essa língua como Língua Materna (L1) em casa, com os pais, normalmente utilizando-a no dia-a-dia da família e, em vários casos, da comunidade. Contudo, sabemos que língua materna é, de acordo com Pupp Spinassé (2006), um termo bastante complexo, que envolve vários fatores, não sendo apenas uma questão cronológica (L1) ou familiar (língua da "mãe" ou "dos pais"). Esses são fatores importantes para se caracterizar uma língua materna, mas não são os únicos que devem ser levados em consideração. A língua materna não é só

\begin{abstract}
(ou não necessariamente só) a primeira língua que eu aprendi ou a língua da minha mãe e do meu pai. Ela vai ser a língua da mãe, ou do pai, ou de outros familiares, ou ainda somente da comunidade onde vivo, mas que domino e utilizo em meu processo de socialização; ela pode ser a língua adquirida por primeiro, mas pode ser uma língua adquirida um pouco depois, com a qual, contudo, o indivíduo estabelece uma relação afetiva ou a qual tenha para ele o melhor status; pode ser a língua do dia-a-dia, a língua predominante na sociedade, mas pode ser também a língua usada em uma comunidade de fala específica; de toda a forma, será uma língua com a qual o indivíduo se identifica e se sente à vontade (PUPP SPINASSÉ, 2017a, p. 227).
\end{abstract}

Assim, o falante de uma língua minoritária como L1 inserido em uma comunidade com uma língua majoritária distinta, por exemplo, acaba aprendendo a língua da comunidade (por exemplo, ao entrar para a pré-escola), sendo, mais tarde, um adulto que irá dominar essa língua majoritária com grande propriedade para suas funções específicas e estabelecendo com ela, na maioria das vezes, uma relação afetiva forte, já que se sente à vontade e identificado com a mesma. Então, enquanto a língua minoritária preenche alguns dos critérios mencionados acima para ser considerada língua materna, a língua majoritária preencherá outros desses critérios, sendo ambas parte identificadora desse indivíduo (PUPP SPINASSÉ, 2017a, p. 228). Portanto, ambas serão suas línguas maternas, caracterizando o que chamamos de bilinguismo precoce.

É sabido que existem várias definições sobre bilinguismo (vide BLOOMFIELD, 1933; MACKEY, 1972; MCLAUGHLIN, 1984; SAUNDERS, 1988; ROMAINE, 1995; GENESEE, 2004; 
MEISEL, 2004; entre outros), mas não queremos entrar nessa questão terminológica neste artigo, por não ser o foco, já que os participantes se encaixam em praticamente todos os tipos de definição sobre "bilíngue". Contudo, para deixar claro o nosso entendimento sobre o conceito, podemos dizer que ser bilíngue (ou plurilíngue ${ }^{6}$ ) é, resumidamente, conseguir performar em mais de uma língua, de forma relativamente natural, para suas respectivas funções. Ou seja, o indivíduo consegue gerenciar (falar e/ou entender) duas ou mais línguas, utilizando cada uma para os respectivos contextos e propósitos necessários, com a propriedade necessária.

Usamos o termo Língua de Imigração para determinar aquelas línguas alóctones (ou neo-autóctones ${ }^{7}$ ) que chegaram ao país através de ondas migratórias, constituindo, aqui, comunidades de fala (vide OLIVEIRA, 2003). Esse é o caso, por exemplo, do Hunsrückisch (ou hunsriqueano ${ }^{8}$ ), do talian, do pomerano e do polonês no Brasil, línguas que foram trazidas, há mais de um século (em parte já há quase dois séculos), com os imigrantes que aqui se estabeleceram, sendo passadas "de pai para filho" e sendo praticadas no dia a dia das comunidades dos descendentes de imigrantes para diversas funções.

Cabe lembrar que, como continuaram a se desenvolver de forma independente no Brasil, as línguas de imigração acabaram se distanciando um pouco de suas respectivas matrizes, sendo influenciadas pelo contato linguístico com o português, principalmente, e com outras variedades de outros grupos de imigrantes que habitavam a mesma região. Devido a esse processo, costuma-se conferir a essas línguas de imigração históricas o status de língua brasileira ${ }^{9}$, mesmo que, no corpus, elas ainda claramente remetam à sua origem (PUPP SPINASSÉ, 2016, p. 108).

Diferentemente das línguas de imigração, uma Língua de Herança (LH) não tem status de língua local (vide BORUCHOWSKI; LICO, 2016, p. 9) - pelo menos não enquanto configure uma língua de herança por definição. Ela também é uma língua minoritária e/ou minorizada, por estar inserida em meio a uma sociedade que fala outra língua - majoritária de forma oficial, sendo restrita a um grupo social ou mesmo apenas ao ambiente familiar do indivíduo. ${ }^{10}$

Se um casal libanês, por exemplo, deixa o Líbano para, por qualquer motivo que seja, residir no Brasil, eles trazem a língua árabe libanesa consigo e vão falar com os filhos

\footnotetext{
${ }^{6}$ É importante esclarecer que, em consonância com Mackey (2013), consideramos "bilíngue" e "plurilíngue" como sinônimos, já que ambos os termos remetem às mesmas características sociais, diferenciando-se apenas no que diz respeito à quantidade de línguas faladas - o que, para as nossas análises aqui, não é relevante.

${ }^{7}$ Vide Savedra; Mazzelli-Rodrigues, 2017.

${ }^{8}$ Apesar de haver a denominação "hunsriqueano" em português, optamos por continuar utilizando o termo germânico "Hunsrückisch", por ser a forma que os falantes reconhecem. O termo "Hunsrückisch" faz parte do vocabulário dessa variedade, enquanto "hunsriqueano" foi uma criação in vitro (vide CALVET, 2002, p. 146) para facilitar a pronúncia de brasileiros. Como optamos pela forma germânica, seguimos, de acordo com as diretrizes postuladas pelo grupo ESCRITHU (ALTENHOFEN et al., 2007), a grafia de tradição alemã, escrevendo o termo com a primeira letra maiúscula, como é de costume também na literatura científica a respeito.

${ }^{9}$ Vide http://forlibi.blogspot.com/. Acesso em: 26 mar. 2020.

${ }^{10}$ A língua de herança pode ser, muitas vezes, até mesmo invisível aos olhos da sociedade em volta, se o número de falantes não for considerável.
} 
pequenos em solo brasileiro - independentemente se nascidos aqui ou também imigrados esse idioma. Contudo, a língua árabe libanesa falada em casa sofrerá grande - e até mesmo desleal - concorrência com o português, já que é a língua falada pelos vizinhos, pelos amigos, pela comunidade local, pela comunidade escolar, pelos meios de comunicação e pela sociedade em geral. É muito comum, por exemplo, que as crianças parem de falar a língua de herança - interessando-se por ela, inúmeras vezes, mais tarde, quando têm que recorrer a aulas para recuperar os conhecimentos linguísticos e a fluência perdidos.

No momento em que a criança de origem emigrante entra no infantário ou na pré-escola e começa a construir relações sociais fora do núcleo familiar, o contacto com a língua maioritária [sic] ${ }^{11}$ cresce consideravelmente (...). Rapidamente, esta passa a ser a língua preferida da criança, falada com os amigos, os professores e os irmãos. Em muitos casos, a partir deste momento, a língua maioritária também passa a ter um papel muito mais importante enquanto língua de comunicação na família. E se um dos pais é ele próprio já emigrante de segunda geração e/ou falante nativo da língua maioritária (com ou sem conhecimentos da língua minoritária), a presença da língua maioritária no seio da família é ainda mais forte e o contacto com a LH mais restrito. O que caracteriza então o FH [Falante de Herança] é esta exposição simultânea, mas desequilibrada às duas línguas. Este contacto limitado com a LH torna-se um fator-chave, não só comparando o grau de exposição às duas línguas do próprio falante, mas também se confrontarmos o seu grau de exposição à LH com a de um falante da mesma idade que só a ela esteja quotidianamente exposto (FLORES; MELO-PFEIFER, 2014, p. 231).

Apesar de haver paralelos entre o que é denominado língua de imigração e o que é denominado língua de herança ${ }^{12}$, há também diferenças cruciais: o que conhecemos sob o termo de língua de imigração no Brasil são variedades que se tornaram independentes da matriz e constituem uma comunidade de fala, ou seja, mesmo fora do seio familiar é possível utilizar a língua em diversas relações sociais. O que caracterizamos como língua de herança é uma língua familiar, adquirida pela primeira ou segunda geração nascida no novo país na infância, ainda identificada linguística e socialmente (em corpus e em status) com sua origem; é a língua de origem do imigrante (vide BORUCHOWSKI; LICO, 2016, p. 11). A língua de imigração, por sua vez, remete a uma identidade étnica histórica, à origem dos antepassados, não necessariamente à própria.

Contudo, como tanto as línguas de imigração quanto a língua de herança presentes em nossa pesquisa configuram línguas minoritárias, trataremos, neste artigo, ambos os tipos da mesma forma. Ou seja, fazemos uma distinção conceitual, mas a análise será a mesma, já que o foco são as línguas minoritárias, o que todas elas são.

Existem muitas crenças e mitos relacionados a línguas minoritárias (HILGEMANN, 2004; PUPP SPINASSÉ, 2016), especialmente em um país que sempre pregou o

\footnotetext{
${ }^{11}$ Seguindo o que se usa fazer em português brasileiro (PB), adotamos o termo "Língua Majoritária", e não "Língua Maioritária". Contudo, deixamos assim aqui por ser uma citação direta das autoras portuguesas.

12 O termo Língua de Herança não é unânime, e autores (vide FRITZEN, 2008; 2012; BOAS; FINGERHUT, 2017; JOHANNESSEN; SALMONS, 2016) o utilizam paralelamente à ou para substituir a denominação Língua de Imigração. Neste artigo defendemos a distinção entre os termos, conforme explicitado acima.
} 
monolinguismo, como o Brasil (CAVALCANTI, 1999; MARIANI, 2008). Isso acaba fazendo com que as línguas minoritárias não valorizadas no "mercado linguístico"13 (línguas de imigração e, em muitos casos, línguas de herança) sofram com preconceito linguístico e com atitudes linguísticas negativas, não só por parte da sociedade em geral, mas também por parte dos próprios falantes (vide SCHNEIDER, 2007; MARTINY, 2017).

A título de ilustração, citamos aqui os mitos mais frequentes que encontramos tanto em pesquisa de campo quanto na literatura (vide HILGEMANN, 2004; ALTENHOFEN, 2004):

- "Brasileiro fala português"

- "O Brasil é um país monolíngue"

- "A língua minoritária é uma língua ruim"

- "Falar a língua minoritária além do português pode confundir a criança, ser prejudicial na aprendizagem"

- "Falar a língua minoritária vai fazer com a que criança troque as letras, pode prejudicar a alfabetização em português"

- "O bilíngue não sabe bem nem uma língua nem outra"

- "Falar a língua minoritária vai fazer com que a criança tenha sotaque"

Em pesquisas de campo em contextos de línguas minoritárias brasileiras de imigração, frequentemente ouvimos depoimentos de falantes que sentem vergonha por falarem a respectiva variedade, já que a costumam considerar como uma língua menor, uma língua "errada", uma língua "ruim", apresentando o que Calvet (2007, p. 72) denomina de insegurança linguística. Muitas vezes, esses mitos têm origem em questões linguísticas, já que, tendo se desenvolvido longe da matriz e tendo experienciado situações de contato linguístico e, consequentemente, de empréstimos (sobretudo lexicais), costumam-se considerar as diferenças em relação à matriz como corrupções linguísticas, erros e empobrecimento da variedade (PUPP SPINASSÉ, 2017).

Além de questões linguísticas, também questões sociais desempenharam um papel importante para se chegar à atual situação de desprestígio das línguas brasileiras de imigração: os imigrantes que aqui chegavam geralmente eram assentados em regiões isoladas ou afastadas, já que a ocupação do território ocioso e a criação de uma classe de cidadãos livres trabalhadores rurais, baseada no regime econômico de pequenas propriedades rurais, na agricultura familiar e na policultura eram os principais objetivos da campanha de imigração do governo imperial brasileiro (vide DREHER, 2005). Isso faz com que as línguas de imigração sejam diretamente ligadas ao "ser colono", e, consequentemente, a um contexto e a um falar mais "pobre" (com menos cultura e menos escolarizado) e estigmatizado. Línguas de imigração são, portanto, conforme pudemos observar em discursos individuais e mesmo em meios de comunicação a que já tivemos acesso em pesquisas de campo, frequentemente usadas para fazer piadas e são, novamente,

\footnotetext{
${ }^{13}$ Remetemos aqui à ideia de Bourdieu (1977), segundo o qual o valor de uma língua corresponde ao valor que atribuem a seus falantes. Trata-se de enxergar a língua não só como uma questão social, mas como uma questão política e econômica, de poder e autoridade (vide também BRANDÃO, 2017).
} 
ligadas a situações de desprestígio (vide HILGEMANN, 2004, p. 93).

Esse status negativo conferido às línguas de imigração influencia também na decisão do falante em prol ou não da manutenção da língua, ou seja, em usá-la ou não em casa, em passá-la ou não para os filhos. São as decisões e as práticas linguísticas da família, portanto, que determinam se uma língua será adquirida e mantida, ou se será perdida e deixada de lado.

Segundo Spolsky (2004), o estudo das políticas linguísticas inclui a análise das crenças ou ideologias sobre a linguagem (ou seja, o que as pessoas pensam sobre as línguas), as práticas linguísticas (o que as pessoas fazem com as línguas) e os esforços para modificar ou influenciar essas práticas através de intervenções linguísticas ou planejamento (o que as pessoas tentam fazer com as línguas). Tais políticas podem ser públicas ou privadas. No âmbito das políticas linguísticas privadas, encontram-se, por definição, as políticas linguísticas familiares, onde se incluem as crenças, por exemplo, sobre o processo de aquisição da linguagem, sobre línguas específicas e sobre a relação entre línguas e inteligência. Por sua vez, essas crenças ou ideologias ligam-se a atitudes sociais mais amplas em relação a certos segmentos da população, como aos imigrantes e às minorias étnicas, assim como às práticas e aos estilos familiares (vide KING; FOGLE; LOGAN-TERRY, 2008).

As crenças sobre questões linguísticas definem, por conseguinte, comportamentos e práticas, e acabam por produzir "verdades". Segundo Silva (2014, p. 1369), "as práticas sociais relacionadas à língua(gem) explicitam um forte preconceito linguístico relativo às línguas minoritárias, assim como às variantes não prestigiadas do português". Assim, os esforços para promover ou não o bilinguismo em contextos de línguas minoritárias não acontecem apenas de maneira inconsciente, mas são, antes de tudo, o resultado das decisões tomadas pelas famílias, isto é, pelas políticas linguísticas familiares, cujo planejamento pode ser explícito ou tácito e se referem ao uso das línguas dentro da casa e entre os membros daquela família (vide KING; FOGLE; LOGAN-TERRY, 2008).

Por tais motivos, buscamos analisar membros de famílias bilíngues, a fim de averiguar as políticas linguísticas presentes no nosso recorte de pesquisa.

\section{O Projeto de pesquisa}

O projeto "Políticas linguísticas familiares - ideologias subjacentes" foi desenvolvido por nós, vinculado à Universidade Federal do Rio Grande do Sul, ao longo de um ano. Tratouse de uma pesquisa de caráter qualitativo, composta por uma parte intensa de revisão bibliográfica e uma etapa de pesquisa de campo, coletando-se dados através de questionários e entrevistas, que foram realizados com membros de famílias bilíngues independentemente do par de línguas e do status das mesmas.

Buscamos identificar, primeiramente dentre nosso círculo de conhecidos, pais e mães de famílias plurilíngues, ou seja, famílias nas quais mais de uma língua coexistem - tanto (1) as que usam mais de uma língua em casa quanto (2) as que não o fazem, embora sejam compostas por membros bilíngues ou por membros que tenham originalmente línguas 
diferentes, bem como (3) as famílias com uma única língua familiar, mas inseridas em ambiente onde outra(s) língua(s) seja(m) empregada(s). Utilizando o método bola de neve ${ }^{14}$, solicitamos que os primeiros participantes contatados nos indicassem outros indivíduos com esse perfil (membro de família plurilíngue), a fim de deixar a amostra mais plural e heterogênea.

O objetivo da pesquisa era averiguar as práticas e decisões linguísticas nessas famílias, a fim de analisar as consequências que as ideologias levantadas produziram na escolha de se "bilinguar"15 ou não os filhos. Sabemos que decisões tomadas no seio das famílias plurilíngues são definidoras em relação à manutenção ou ao abandono de um ou outro idioma e também decisivas sobre a criação monolíngue ou bilíngue dos filhos. Buscávamos, portanto, descrever as ideologias linguísticas presentes para a ocorrência dos regimes linguísticos familiares, analisando as diferenças nos discursos das famílias que optaram e que não optaram por bilinguar seus filhos, para pensarmos, para mais adiante, estratégias de promoção do plurilinguismo. Desvelando mitos e/ou outros motivos que estejam impedindo pais de bilinguarem os seus filhos, esperamos, a partir dos resultados, poder auxiliar famílias e professores com informações esclarecedoras, evitando que se deixem de formar novos falantes bilíngues por causa de desconhecimento ou de influência de ideologias monolíngues.

O questionário, que continha 37 perguntas, foi mobilizado pessoalmente, em forma de entrevista, ou foi enviado por e-mail para os participantes que moravam em lugares distantes. Era composto por perguntas fechadas, com respostas sim ou não, e por perguntas abertas, em que os informantes puderam explicar suas escolhas e as motivações para elas. Obtivemos, no total, dados de 42 pessoas, falantes dos mais diferentes pares de línguas. ${ }^{16}$ Para este artigo, contudo, apresentaremos os dados de cinco informantes, aqueles que possuem uma assim denominada língua minoritária como língua familiar.

\section{Dados coletados}

Os informantes que apresentaremos a seguir são brasileiros, bilíngues equilibrados ou balanceados ${ }^{17}$ de português e de uma língua minoritária, aqui presente em função da

\footnotetext{
${ }^{14}$ A técnica metodológica snowball, também denominada snowball sampling ou "bola de neve", é muito usada em pesquisas com comunidades em que se quer uma amostra não probabilística. Usa-se quando não interessa determinar a probabilidade de seleção de cada informante. Os participantes iniciais de um estudo indicam novos participantes e assim sucessivamente (BALDIN; MUNHOZ, 2011).

${ }^{15}$ Termo empregado por Mozzillo em aulas e palestras, com o sentido de fazer adquirir de maneira natural uma outra língua a uma criança durante a primeira infância em contextos de lares bi/plurilíngues. Ambas as autoras passarão a utilizá-lo doravante em trabalhos escritos, devido à facilidade de compreensão que promove.

${ }^{16}$ No escopo total do projeto de pesquisa, apareceram 15 línguas: português, alemão standard, árabe libanês, croata, espanhol, estoniano, francês, hindi, hunsriqueano, ídiche, inglês, italiano, polonês, pomerano e russo.

17 Segundo Megale (2005, p. 3), trata-se de "Indivíduo que possui competência linguística equivalente em ambas as línguas".
} 
migração de suas famílias ao Brasil. ${ }^{18}$ De acordo com as normas éticas (e com o que constava no Termo de Consentimento Livre e Esclarecido (TCLE) assinado por todos os participantes ${ }^{19}$ ), usaremos aqui pseudônimos para eles. Assim, Aline é falante de polonês; Guido, de hunsriqueano; Marta, de pomerano; Martino, de talian; e Vera, de árabe libanês.

Como já mencionado, o questionário era composto por 37 perguntas; para este artigo, selecionamos oito delas, que trazem informação relevante ao tema que estamos abordando, ou seja, línguas minoritárias. As respostas, replicadas aqui seguindo a ordem alfabética dos pseudônimos dos participantes, foram copiadas exatamente como foram escritas nos questionários que os informantes Aline, Guido, Marta e Martino nos enviaram. As respostas dadas oralmente na entrevista realizada com Vera foram aqui transcritas.

(1) Havia mais de uma língua na tua casa durante a tua infância? Quais? Por quê?

Aline: Sim, duas, o polonês e o português porque minha mãe e meus avós, com quem morava, falavam o polonês e o português. O polonês era falado pelas outras famílias da comunidade, bem como o português.

Guido: Sim. Minha língua materna é um dialeto do alemão, mas falava-se também português, quando necessário. Geralmente com pessoas de fora do meio familiar. A língua de casa era o dialeto Hunsrückisch. Não havia relação com o português, mas quando necessário falava-se. Aos seis, indo para a escola, tive que usar o português.

Marta: Sim. Português e pomerano. A língua mais presente era o pomerano, mas havia também o português, principalmente quando era necessário se deslocar para a cidade de Pelotas. Na escola, o português passou a se tornar mais presente, por ser a língua de escolarização. O pomerano não era a língua do mundo exterior, no caso, fora dos limites da comunidade local.

Martino: $O$ italiano ${ }^{20}$ e o português, por causa da descendência dos meus pais.

Vera: Libanesa e portuguesa. Meus pais eram libaneses e se falava mais libanês um com o outro.

(2) A tua familia de origem veio de um lugar onde se fala/m outra/s língua/s? Em que época?

Aline: Sim, no final do século XIX, início do século XX. Polônia.

Guido: Meus antepassados vieram da Alemanha, mas há muito tempo.

Marta: Meus antepassados vieram da Pomerânia, atualmente, o território pertence à Alemanha. Chegaram ao Rio Grande do Sul por volta de 1856, na região de São Lourenço do Sul, fugindo da disputa que havia do território da Pomerânia pelos poloneses e alemães.

\footnotetext{
${ }^{18}$ A situação linguística dos demais informantes da pesquisa não deriva dessa configuração, por isso não foram selecionados para o recorte deste artigo.

${ }^{19}$ Projeto aprovado pela Comissão de Pesquisa da Universidade e pelo Comitê de Ética em Pesquisa da UFRGS, parecer no 3.064.372.

20 É importante ressaltar que entendemos aqui "italiano" como sinônimo de "talian", já que os falantes de talian no RS também denominam sua língua como italiano, apesar de ser diferente do idioma praticado atualmente na Itália, como o próprio informante declara na pergunta apresentada aqui sob o número 2.
} 
Martino: Meus avós de ambas as partes vieram da Itália ainda crianças na década de 1940. Minha família, mãe e pai, não pensam sobre isso, apenas falam, mas têm consciência de que o italiano falado por eles não é o mesmo da Itália... sabem que é uma língua que nasceu com a mistura do português e do italiano.

Vera: Líbano. Em 1930 mais ou menos. Não tenho bem certeza, acho que é isso.

Como podemos observar, trata-se aqui, neste recorte dos participantes falantes de línguas minoritárias, de quatro casos de uso de língua de imigração (polonês, Hunsrückisch, pomerano e italiano/talian), segundo as definições apresentadas na seção de Pressupostos Teóricos, e de um uso de língua de herança (árabe libanês). Em todos os contextos, havia a presença da língua minoritária e do português no lar durante a infância, sendo que em três casos fica explícito que a língua minoritária era mais utilizada na família e o português privilegiado para o contato externo.

(3) Consideras que essas línguas que te rodeavam na tua infância são tuas línguas maternas? Por quê?

Aline: Sim, porque o polonês vem da minha família e o português é a língua do País.

Guido: Sim, cresci com as duas e sem perceber usei as duas a partir dos seis anos.

Marta: Sim. Aprendi as duas línguas de forma natural e paralela. Não sei definir qual possivelmente aprendi primeiro.

Martino: Sim. Porque cresci e aprendi desde pequeno essas duas línguas.

Vera: ... sim ... materna porque dos meus pais e a gente falava mais isso. Desde que eu era pequena, que eu comecei a falar e aprender eu tive contato. Sempre foi a língua que era dentro da minha casa. Aprendi primeiro a língua portuguesa e depois a libanesa. Mais dificuldade com a libanesa porque convivia com mais pessoas brasileiras.

Contrariando em parte a nossa hipótese inicial, todos os falantes consideraram as duas línguas como suas línguas maternas. Isso é um dado bastante interessante, pois mostra que eles reconhecem as diferentes funções das diferentes línguas, não considerando apenas o critério cronológico ou o critério prestígio para a classificação - o que vai bem ao encontro da definição de língua materna que adotamos na seção dos Pressupostos Teóricos.

(4) O desempenho em cada uma delas foi sempre o mesmo ou em alguma/s houve retrocesso em relação a outras aprendidas depois? ${ }^{21}$

Aline: O desempenho no polonês diminuiu depois que eu saí da casa da minha mãe.

Marta: O desempenho do pomerano e do português sempre foi o mesmo até os 14 anos, quando ingressei no ensino médio. A partir daí, a comunicação em português se tornou mais recorrente. $O$ preconceito em relação ao pomerano, gerou em mim um sentimento de vergonha em relação à língua. Contudo, ao retornar para meu local de origem, não consegui parar de me comunicar em pomerano.

\footnotetext{
${ }^{21}$ Guido relatou aqui sobre outras línguas aprendidas, mas em relação ao Hunsrückisch afirmou que seu desempenho continua normal; Vera não respondeu a essa pergunta.
} 
Martino: Nasci numa família de descendentes de Italianos e desde sempre ouvia o português e o italiano dentro de casa e na comunidade onde me criei. Compreendo tudo do italiano, porém não produzo, deve ser porque nunca fui cobrado em casa. Produzo de forma natural quando demonstro grandes emoções como: alegria, tristeza, raiva, julgamentos...

Aline, Marta e Martino relatam terem diminuído seu desempenho na língua minoritária ao crescerem, ao saírem de casa, sendo que Marta chega a citar o preconceito em relação à língua minoritária e a vergonha como fatores que colaboraram para tal, mesmo que, em casa, tenha mantido o pomerano. Ademais, Martino se queixa de não ter sido "cobrado" e de ter um italiano mais passivo do que ativo. A diminuição do desempenho declarada pelos participantes mostra como o português passou a ser mais dominante, mas, aliado a outras declarações, também pode ser um indício do desinteresse em continuar falando essas línguas minoritárias - que pode ter diferentes motivações.

A partir das respostas obtidas nesta pergunta 4, podemos observar como a língua minoritária está ligada ao seio familiar, às lembranças da infância e à expressão de emoções - o que faz com que as questões que envolvem essa língua materna imediatamente se liguem a questões familiares e emotivas. Assim, qualquer atitude negativa ou traumática relacionada à língua minoritária pode afetar profundamente o falante, influenciando as suas percepções e suas decisões a ela relacionadas.

(5) Sofres algum preconceito por usares alguma língua em particular? Por parte de quem? Em que situação?

Aline: Não, porque já quase não uso mais o polonês no dia a dia, só com familiares.

Guido: Não, pelo contrário, recebo apoio.

Marta: Atualmente não sofro tanto preconceito. Mas na adolescência sofri bastante preconceito na escola, pelos colegas, pela influência do pomerano quando me comunicava em português.

Martino: Muitas vezes quando falo alguma palavra em português e a pronúncia deveria ser com RR e falo com R (fraco) devido à influência do italiano, sofro preconceito sim. 0 pessoal ri, faz chacota e ainda dizem assim: "fala direito alemão". Eles que erram... pois não sou alemão! Não dou importância às barbaridades que escuto. Minha esposa corrige algumas palavras que por influência do italiano acabam interferindo na fala, para que posteriormente a nossa filha não aprenda de forma "errada".

Vera: Sim, sim, porque às vezes no escrever eu trocava as palavras, até no falar às vezes eu misturava um pouco do libanês com o português. Os professores, às vezes, eles falavam e diziam que eu tinha que aprender mais, pegar mais no vocabulário, mas foi bem difícil, porque eu aprendia as duas línguas: português e libanês, e me confundia muito no falar, às vezes mais no escrever. 
(6) Os teus professores e/ou os do teu filho demonstram/demonstraram contrariedade ou temor pelo fato de falares/falarem mais de uma língua? ?2 $^{22}$

Guido: Na universidade um professor, um dia, disse que seria interessante que eu "esquecesse" um pouco do meu dialeto quando estivesse estudando alemão padrão.

Observamos que todos relataram momentos de preconceito, seja na escola, na universidade ou com amigos. Aline diz não sofrer mais, porque usa o polonês só com sua família de origem, o que implica dizer que já foi vítima de alguma situação desagradável em algum momento da vida e que, ao não praticar o polonês em público, evita também qualquer manifestação de preconceito para com sua língua.

É importante destacar que, pela fala dos nossos participantes, o ambiente escolar parece ter sido o mais marcado pelo preconceito linguístico, e que o fato de não sofrerem mais preconceito hoje pode estar ligado ao fato de não estarem mais nesse contexto e de terem aprendido a gerenciar suas situações de uso para evitar essas situações.

(7) Que língua transmites ao teu filho? Como e por que tomaste essa decisão?

Aline: Português porque o português é a língua nacional. Porque onde moro agora não se fala polonês e, na escola, poderia gerar problemas de comunicação aos meus filhos.

Guido: Alemão padrão e português. Em conjunto com minha esposa, optamos por ensinar a língua alemã padrão aos nossos filhos. Somos professores de alemão.

Marta: Pomerano e português. São minhas línguas maternas, portanto fazem parte de mim.

Martino: Apenas o português. Porque é a que domino melhor e a outra não é habitual. Creio que deveria melhorar mais, pois devido à influência do italiano meu português ficou prejudicado principalmente na escrita.

Vera: A brasileira, a libanesa um pouco, algumas coisas. Não transmiti a libanesa porque eu na minha infância no colégio ... depois eu tive muita dificuldade com a língua libanesa e portuguesa, eu misturava um pouco então eu não queria que elas passassem por isso aí, mas ensinei algumas palavras, mas mais assim, de brincadeira.

(8) Te arrependes de teres falado uma determinada língua com o teu filho? Ou de não teres falado? Por quê?

Aline: Sim, de não ter falado, porque seria bom pra eles saber outra língua além do português.

Guido: Não.

Marta: Meu filho ainda não fala, pois tem 1 ano. Não me arrependo de estar falando em pomerano com ele.

Martino: Não. Porque é a língua mais usada na cidade e o italiano só falo em casa e algumas expressões, até mesmo porque não tenho onde praticar e por isso ele vai acabar sumindo.

\footnotetext{
${ }^{22}$ A essa pergunta, Marta e Vera não responderam; Aline e Miguel declararam apenas "não".
} 
Vera: não me arrependi nem um pouquinho porque as minhas filhas vivem mais no meio... o pai delas é brasileiro e a gente não fala mais, depois que eu perdi meus pais, a gente não fala mais a língua libanesa. Meus pais falavam muito libanês. Os amigos dos meus pais iam todas as noites pra lá, pra conversarem e vinham do Líbano, se reuniam na casa do me pai, era uma reunião muito grande e eu gostava dessa união e dessa amizade, assim... como é que eu vou dizer, saía mais a língua libanesa do que a brasileira. Hoje converso com a minha irmã, conversamos sim, mas não assim, falar como se fala o brasileiro não. Só coisas comuns. Quando eu quero dizer alguma coisa pra ela, assim, que não é pros outros ouvirem, eu digo.

Apesar de todos os informantes consideram que as línguas que falam ao lado do português são suas línguas maternas, ou seja, todos assumem ter duas L1, vemos que quatro deles optaram por transmitir ao filho apenas uma dessas L1 - a majoritária. Somente Marta fala com o filho a sua língua de imigração, o pomerano. Guido também está "bilinguando" o filho, mas em outra língua que não adquiriu em situação natural na infância. Aline, Martino e Vera optaram por omitir a língua minoritária do repertório da(s) criança(s) em prol do uso do português, "língua nacional", "língua do país".

Marta parece transmitir com sucesso sua língua minoritária à criança e não se arrepende de falar pomerano com o filho. Assim, podemos concluir que ela é a que mais se dedica a transmitir sua língua, mostrando uma política linguística familiar mais propensa ao bilinguismo.

Guido também bilingua os filhos e não se arrepende da escolha que fez de falar alemão standard com as crianças, em vez de Hunsrückisch, sua L1. Apesar de ele afirmar não sofrer mais preconceito hoje em dia e até receber apoio por falar uma língua minoritária, optou por não a transmitir aos seus filhos no processo de bilinguá-los, o que pode ser considerado contraditório e pode nos dar indícios de alguma influência do status da língua em sua decisão, como seu desprestígio e/ou "falta de utilidade".

Martino e Vera também acham bem não terem falado sua outra língua com os filhos, pois consideram que essa prática teria sido prejudicial para eles. O mesmo declarou Aline, quando falou sobre sua opção de não bilinguar seus filhos: "português é a língua nacional. (...) e, na escola, poderia gerar problemas de comunicação aos meus filhos". Contudo, no caso de Aline parece ter havido arrependimento por essa opção, como ela declarou, apontando para o fato de essa decisão ter sido baseada em fatores que hoje em dia talvez não pareçam mais tão relevantes e/ou apropriados.

Martino e Vera acreditam ainda, segundo suas declarações na Pergunta 5, que o português deles sofreu prejuízo pelo fato de falarem italiano e árabe libanês, respectivamente. A esposa monolíngue de Martino corrige seu português, e Vera tem a convicção de que se confundia nas duas línguas por causa do bilinguismo. Eles também parecem não ver utilidade nas suas respectivas línguas minoritárias - o que também é dado a entender por Aline, quando declara que não ensinou polonês aos filhos por não se falar polonês onde ela mora. 
É importante lembrar que as comunidades de imigrantes não são uniformes e vários fatores explicam a maior ou menor transmissão e manutenção da língua: se são urbanas ou rurais, qual o valor dado pelos pais à língua dos antepassados, se existem ou não políticas públicas contrárias ao bilinguismo, se há uma visão negativa do grupo de fala em questão, se há ou não manifestações sociais da língua, como cartazes nas ruas, etc. (vide SCHWARTZ; VERSCHIK, 2013). Assim, as escolhas das famílias bilíngues para o processo de transmissão intergeracional da língua de casa são consequência dos processos de políticas linguísticas estatais, do status linguístico da comunidade, da construção discursiva do lugar, das atitudes linguísticas das pessoas envolvidas (falantes e não falantes), da percepção dos pais sobre o perigo ou não de se perder a língua (majoritária ou minoritária), das suas ideias sobre o que é bilinguismo e do que pensam sobre certas línguas.

Segundo Deprez, Varro e Collet (2014), o status de cada língua no ambiente social explica as decisões tomadas dentro da família, quando se trata de escolher as línguas a serem passadas aos filhos. Contudo, existem mais elementos orientando essas escolhas. 0 preconceito sofrido em situação de chegada à escola de pessoas oriundas de uma comunidade onde se usa a língua minoritária determina, em grande medida, a decisão, consciente ou não, de não empregar com os filhos a língua que as fez sofrer preconceito.

A questão do preconceito na escola ainda ocorre em regiões com alta presença de comunidades falantes de línguas minoritárias de imigração (vide HILGEMANN, 2004; SCHNEIDER, 2007; PUPP SPINASSÉ, 2016). Embora os informantes aqui apresentados declarem não sofrerem mais preconceito, é importante lembrar que eles não estão mais em situação escolar; ou seja, a declaração deles pode ilustrar uma realidade diferente da que observamos em pesquisa de campo nas comunidades quando em contexto escolar. $E$, conforme pontua Finger (2008, p. 73), “as línguas dessas comunidades já sofreram, ao longo de suas gerações, uma série de ações avaliativas punitivas, de desvalorização e, o que é mais lamentável, de anulação da identidade linguística".

Nesse sentido, muitas escolas também ainda creem que a língua de casa é elemento prejudicial para a aquisição do português. Geralmente ignoram-se as questões de identidade e não se valoriza a forma de falar e de pensar dos alunos, que, muitas vezes, vivem em situação de diglossia ${ }^{23}$, por conta da vergonha que pode se instalar e do ressentimento que pode surgir com relação à identidade dupla. Isso tudo tem impacto nas políticas linguísticas familiares.

Existe, portanto, uma ideologia linguística, citada pelos participantes da pesquisa, de que o português que falantes de línguas minoritárias falam não seria bom, ou que as crianças apresentariam determinados desvios por terem adquirido o português mais tardiamente. Isso também influencia pais a decidirem contra o bilinguismo precoce de seus filhos, a fim de evitar o "sotaque" e outros problemas nesse sentido, como vimos nas declarações aqui trazidas. Contudo, isso é fruto do desconhecimento de que, até os 10 anos,

\footnotetext{
${ }^{23}$ Aqui compreendida como a situação em que duas línguas convivem na mesma região, sendo que uma delas, ao possuir mais prestígio social por ser a oficial do país, relega a outra a funções tidas como menores pelos falantes (vide FISHMAN, 1967).
} 
aproximadamente, havendo contato prolongado em situação natural de aquisição, a outra língua (no caso, o português) é desempenhada como "nativa" (vide MOZZILLO, 2001). Esse é o caso típico de falantes de línguas minoritárias em casa, que adquirem a língua majoritária no sistema escolar por volta dos 6 ou 7 anos, como ocorreu com alguns de nossos participantes.

Mesmo em alguns estudos da academia ou dentro das escolas, como pudemos observar, existe, ainda hoje, a ideia de que as características negativas do português desses falantes se devem ao bilinguismo individual, como se falassem uma interlíngua ${ }^{24}$ do português, um sistema imperfeito, em construção, influenciado com elementos de sua única língua materna, a de imigração. Entretanto, sabemos que isso não procede e que a língua de imigração é uma variedade de contato; assim, todos os falantes da região falam português com tais elementos, pertencendo ou não à etnia, falando ou não a língua de imigração - ou seja, sendo ou não bilíngues.

Para Da Silva (2015), muitas famílias não falam com os filhos a sua língua de origem por terem tido pouca instrução formal e porque isso provoca sentimentos de vergonha. Por causa disso, optam por falar a língua da escolaridade das crianças, até para poderem auxiliálas nas tarefas de casa e incluí-las nos grupos sociais de maior prestígio. Isso explica a opção de não falar com o filho na língua de imigração, por se tratar de um "mau italiano" ou de um "alemão agramatical" ou de "apenas um dialeto", como já ouvimos em campo, ou para poupá-lo de problemas com o português.

O segredo de criar bilíngues precoces é permitir que estes tenham acesso a ambientes com mais de uma língua e exigir-lhes a produção em ambas desde cedo -, já que não fazer isso provocará um bilinguismo apenas passivo (vide MOZZILLO, 2015). Ainda que sejam capazes de compreender e de dizer algumas palavras, não conseguirão ter as habilidades de produção, como vemos exposto nas declarações de Martino.

\section{Conclusões}

A consistência do comportamento dos pais é o principal fator para bilinguar as crianças e isso depende muito da ideologia linguística e da capacidade de manter o bilinguismo iniciado. O que pensam sobre etnia, bagagem cultural, identidade nacional e afeto (também ligado à noção de pátria) influenciará, de forma direta, as práticas linguísticas.

Dessa maneira, a política familiar tem consequências no sucesso escolar, na manutenção da língua de herança e da língua minoritária, na relação com a língua de prestígio social, bem como no histórico de aprendizado e na construção identitária.

A família é o lugar onde a comunidade e o indivíduo se encontram. As crianças se socializam dentro e fora de casa e essa distinção é muito importante quando há situações

\footnotetext{
${ }^{24}$ Termo bastante polêmico, cunhado por Selinker (1972) e definido por Ellis (1995) como um conhecimento que estaria situado, dentro de um continuum da L1 à língua-alvo, em um ponto intermediário, apartado de ambas. Seria um sistema independente, individual de cada falante e em constante mudança.
} 
linguísticas e culturais diferentes dentro e fora. A língua de casa está relacionada a situações emocionais, cognitivas e comportamentais (internas e privadas), enquanto a outra está ligada ao mundo externo, com o qual o indivíduo também se relaciona e se identifica. Muitas vezes, as crianças de grupos de fala minoritários tendem a preferir usar em qualquer contexto a língua dominante - daí a importância de a família insistir no seu uso da língua minoritária dentro de casa.

Sabemos que a qualidade do input importa mais do que a quantidade, por isso, para um processo de aquisição da língua familiar minoritária, torna-se necessário falar com a criança e insistir que ela responda na mesma língua. Quando adultos e crianças falam línguas diferentes, não se respondem na mesma, pode haver efeitos emocionais negativos. A perda da língua pode ser fator de distância emocional entre presente e passado.

Todas as referências a preconceito nas respostas aqui trazidas relatam passagens mais antigas, parecendo este ser um problema menor atualmente. Isso nos dá, por um lado, a esperança de que as próximas gerações de bilíngues teriam menos problemas nesse sentido; por outro lado, contudo, nossos participantes são adultos e, talvez, esse seja um motivo pelo qual estejam mais distantes de manifestações preconceituosas, já que, muitas vezes, é na escola que elas acontecem - o que torna o trabalho junto às escolas bastante necessário. Além disso, no que diz respeito a políticas linguísticas familiares, as atitudes negativas em relação a línguas minoritárias já influenciaram bastante outras gerações em suas decisões linguísticas, o que se reflete até hoje.

Tentamos, assim, com esta pesquisa iniciar um desenho de situações de bilinguismo familiar nos dias de hoje no que diz respeito ao uso de línguas minoritárias, com vistas a dar subsídios para uma discussão mais ampla sobre políticas linguísticas familiares e suas possibilidades. Entendemos que o plurilinguismo é um fenômeno positivo, mas muitos pais deixam de bilinguar seus filhos por não acreditarem, por diversos motivos, que valha a pena a transmissão de uma língua minoritária. Tendo o registro das ideologias de pais bilíngues e entendendo as políticas linguísticas familiares nos é possível traçar ações concretas - como atividades em escolas, exposições em comunidades e a publicação de informativos para o público não acadêmico acerca dessas questões, procurando conscientizar e desconstruir mitos que possam estar influenciando negativamente as decisões das famílias. Acreditamos que todo falante tem o direito de deixar de falar sua língua, mas essa decisão deve ser tomada respaldada pelos esclarecimentos necessários, pois somente assim configura-se realmente em uma decisão própria.

\section{Referências}

ALTENHOFEN, Cléo V. Política lingüística, mitos e concepções lingüísticas em áreas bilíngües de imigrantes (alemães) no Brasil. Revista Internacional de Lingüística Iberoamericana (RILI), Frankfurt, n. 1(3), p. 83-93, 2004.

ALTENHOFEN, C. V.; MORELLO, R. Rumos e perspectivas das políticas linguísticas para línguas 
minoritárias no Brasil: entre a perda e o inventário de línguas. In: FARENZENA, N. (Org). VI Encontro internacional de investigadores de políticas linguísticas. Porto Alegre: UFRGS, 2013. p. 19-26.

ALTENHOFEN, C. V. et al. Fundamentos para uma escrita do Hunsrückisch falado no Brasil. Revista Contingentia, v. 2, p. 73-87, 2007.

BALDIN, N.; MUNHOZ, E. Snowball (bola de neve): uma técnica metodológica para pesquisa em educação ambiental comunitária. In: ANAIS DO X CONGRESSO NACIONAL DE EDUCAÇÃO, 2011, Curitiba. Anais... Curitiba, 2011. p. 329-341.

BLOOMFIELD, L. Language. New York: Holt, Rinehart \& Winston, 1933.

BOAS, H. C.; FINGERHUTH, M. "I am proud of my language but I speak it less and less!" - Der Einfluss von Spracheinstellungen und Sprachgebrauch auf den Spracherhalt von HeritageSprechern des Texasdeutschen. Linguistische Berichte, n. 249, p. 95-121, 2017.

BORUCHOWSKI, I. D.; LICO, A. L. Como manter e desenvolver o português como língua de herança: sugestões para quem mora fora do Brasil. Miami: MUST University; Consulado Geral do Brasil em Miami, 2016.

BOURDIEU, P. L'économie des échanges linguistiques. Langue Française, Paris, n. 34 (Linguistique et sociolinguistique), p. 17-34, 1977. https://doi.org/10.3406/lfr.1977.4815

BRANDÃO, S. M. Mercado linguístico: uma interpretação da imbricada relação estrutura linguística e estrutura social. Linguagem: Estudos e Pesquisas, Catalão (GO), v. 21, n. 1, p. 225-255, 2017. https://doi.org/10.5216/lep.v21i1.52283

CALVET, L.-J. Sociolinguística: uma introdução crítica. São Paulo: Parábola Editorial, 2002.

CALVET, L.-J. As políticas linguísticas. São Paulo: Parábola Editorial, 2007.

CAVALCANTI, M. C. Estudos sobre educação bilíngüe e escolarização em contextos de minorias lingüísticas no Brasil. D.E.L.T.A., São Paulo, v. 15, n. especial, p. 385-417, 1999. https://doi.org/10.1590/S0102-44501999000300015

DA SILVA, E. Sociolinguistic tensions in the Portuguese/Lusophone community of Toronto, Canada. In: MOITA LOPES, L. P. (Org.) Global Portuguese: Linguistic ideologies in late modernity. Londres: Routledge, 2015. p. 125-143.

DEPREZ, C.; VARRO, G.; COLLET, B. Introduction. Langage \& société. Familles plurilingues dans le monde. Mixités conjugales et transmission des langues, Paris, n. 147, 2014. p. 7-22. https://doi.org/10.3917//s.147.0007

DREHER, M. N. Os 180 anos da Imigração Alemã. In: ARENDT, I. C.; WITT, M. A. (Org.). História, cultura e memória: 180 anos de imigração alemã. São Leopoldo: OIKOS, 2005. p. 123-135.

ELLIS, Rod. Understanding Second Language Acquisition. Oxford: Oxford University Press, 1995.

FINGER, L. Contexto multilíngüe: conduta avaliativa e atitudes lingüísticas. A influência de crenças e políticas. Revista Contingentia, Porto Alegre, v. 3, n. 1, p. 69-77, 2008. 
FISHMAN, J. A. Bilingualism with and without Diglossia; Diglossia with and without Bilingualism. Journal of Social Issues, New York, v. 23, n. 2, p. 29-38, 1967. https://doi.org/10.1111/j.1540-4560.1967.tb00573.x

FLORES, C.; MELO-PFEIFER, S. O conceito "Língua de Herança" na perspectiva da Linguística e da Didática de Línguas: considerações pluridisciplinares em torno do perfil linguístico das crianças lusodescendentes na Alemanha. Domínios de Lingu@gem, Uberlândia, v. 8, n. 3, p. 16-45, 2014. https://doi.org/10.14393/DLesp-v8n3a2014-3

FRITZEN, M. P. Desafios para a educação em contexto bilíngue (alemão/português) de língua minoritária. Educação Unisinos, v. 16, n. 2, p. 161-168, 2012.

https://doi.org/10.4013/edu.2012.162.08

FRITZEN, M. P. Ich spreche anders, aber das ist auch deutsch: línguas em conflito em uma escola rural localizada em zona de imigração no sul do Brasil. Trabalhos de Linguística Aplicada, Campinas, v. 47, n. 2, p. 341-356, 2008. https://doi.org/10.1590/S0103$\underline{18132008000200005}$

GENESEE, F. What do we know about: bilingual education for majority language students? In: BHATIA, T. K.; RITCHIE, W. C. (Org.). The Handbook of bilingualism. Oxford: Blackwell Publishing, 2004. p. 547-576. https://doi.org/10.1002/9780470756997.ch21

HILGEMANN, C. M. Mitos e concepções linguísticas do professor em contextos multilíngües. 2004. 159 f. Dissertação (Mestrado em Letras) - Programa de Pós-Graduação em Letras, Universidade Federal do Rio Grande do Sul, Porto Alegre, 2004.

JOHANNESSEN, J. B; SALMONS, J. The study of Germanic heritage languages in the Americas. In: JOHANNESSEN, J. B; SALMONS, J. (Org.) The study of Germanic heritage languages in North America: acquisition, attrition and change. Amsterdam: John Benjamins, 2015. p. 1-20. https://doi.org/10.1075/silv.18.001int

KING, K. A.; FOGLE, L.; LOGAN-TERRY, A. Family Language Policy. Language and Linguistics Compass, v. 2, n. 5, p. 907-922, 2008. https://doi.org/10.1111/j.1749-818X.2008.00076.X

MACKEY, W. F. Bilingualism and multilingualism in North America. In: BHATIA, T. K.; RITCHIE, W. C. (Org.). The Handbook of Bilingualism and Multilingualism. 2. ed. Malden/MA: WileyBlackwell, 2013. p. 707-724. https://doi.org/10.1002/9781118332382.ch28

MACKEY, W. F. The description of bilingualism. In: FISHMAN, J. A. (Org.). Readings in the sociology of language. 3. ed. The Hague: Mouton, 1972. p. 554-584. https://doi.org/10.1515/9783110805376.554

MARIANI, B. S. C. Entre a evidência e o absurdo: sobre o preconceito linguístico. Cadernos de Letras da UFF, Niterói, v. 36, p. 27-44, 2008.

MARTINY, F. M. Atitudes linguísticas em torno da língua de imigração e a sua (não) transmissão. Entrepalavras, Fortaleza, v. 7, p. 297-313, 2017.

https://doi.org/10.22168/2237-6321.7.7.2.297-313

MCLAUGHLIN, B. Second language acquisition in childhood. Hillsdale/N.J.: Erlbaum, 1984.

MEGALE, A. H. Bilingüismo e educação bilíngüe - discutindo conceitos. Revista Virtual de Estudos da Linguagem (ReVEL), v. 3, n. 5, p. 1-13, 2005.

MEISEL, J. M. The bilingual child. In: BHATIA, T. K.; RITCHIE, W. C. (Org.). The Handbook of 
Bilingualism. Oxford: Blackwell Publishing, 2004. p. 91-113.

MOZZILLO, I. A conversação bilíngüe dentro e fora da sala de aula de língua estrangeira. In: HAMMES, W.; VETROMILLE-CASTRO, R. (Org.) Transformando a sala de aula, transformando o mundo: ensino e pesquisa em língua estrangeira. Pelotas: Educat, 2001. p. 287-324.

MOZZILLO, I. Algumas considerações sobre o bilinguismo infantil. Veredas (on-line), Juiz de Fora, v. 19, n. 1, p. 147-157, 2015.

OLIVEIRA, G. M. (org.). Declaração Universal dos Direitos Lingüísticos. Campinas, SP: IPOL/Mercado das Letras, 2003.

PUPP SPINASSÉ, K. Os conceitos de língua materna, segunda língua e língua estrangeira e os falantes de línguas alóctones minoritárias no sul do Brasil. Revista Contingentia, Porto Alegre, v. 1, n. 1, p. 01-10, 2006.

PUPP SPINASSÉ, K. Fazendo política linguística em sala de aula: ações didático-pedagógicas pela manutenção da língua minoritária Hunsrückisch. Revista Virtual de Estudos da Linguagem - ReVEL, v. 14, n. 26, p. 103-119, 2016.

PUPP SPINASSÉ, K. Língua materna, língua estrangeira, língua adicional e as suas relações em um contexto multilíngue do Brasil. In: SILVA, C. L. C.; DEL RÉ, A.; CAVALCANTE, M. C. B. (Org.). A criança na/com a linguagem: saberes em contraponto. Porto Alegre: Instituto de Letras UFRGS, 2017a. p. 223-235.

PUPP SPINASSÉ, K. Contribuição do português para a constituição lexical do Hunsrückisch em situação de contato linguístico. Revista Linguística, Rio de Janeiro, v. 3, n. 13, 2017b. p. 94109. https://doi.org/10.31513/linguistica.2017.v13n3a16385

ROMAINE, S. Bilingualism. 2. ed. Oxford: Blackwell, 1995.

SAUNDERS, G. Bilingual Children: From Birth to Teens. Clevedon: Multilingual Matters, 1988.

SAVEDRA, M. M. G.; MAZZELLI-RODRIGUES, L. A língua pomerana em percurso histórico brasileiro: uma variedade (neo)autóctone. Working Papers em Linguística, Florianópolis, v. 18, n. 1, p. 6-22, 2017. https://doi.org/10.5007/1984-8420.2017v18n1p6

SCHNEIDER, M. N. Atitudes e concepções linguísticas e sua relação com as práticas sociais de professores em comunidades bilíngues alemão-português do Rio Grande do Sul. 2007. 286 f. Tese (Doutorado em Letras). - Programa de Pós-Graduação em Letras, Universidade Federal do Rio Grande do Sul, Porto Alegre, 2007.

SCHWARTZ, M.; VERSCHIK, A. Achieving Success in Family Language Policy: Parents, Children and Educators in Interaction. In: SCHWARTZ, M.; VERSCHIK, A. Successful Family Language Policy: Parents, Children and Educators in Interaction. New York, London: Springer, 2013. p. 1-20. https://doi.org/10.1007/978-94-007-7753-8 1

SELINKER, Larry. Interlanguage. International Review of Applied Linguistics, Boston, v. 10, p. 209-232, 1972. https://doi.org/10.1515/iral.1972.10.1-4.209

SILVA, E. R. da. A pesquisa em política linguística no Brasil: contribuições dos estudos sobre crenças e ensino/aprendizagem de línguas. In: ANAIS DO XVII CONGRESO INTERNACIONAL DE LA ASOCIACIÓN DE LINGÜÍSTICA Y FILOLOGÍA DE AMÉRICA LATINA (ALFAL), 2014, João Pessoa. Anais... João Pessoa, 2014. p. 1356-1365. 
SPOLSKY, B. Family language policy-the critical domain. Journal of Multilingual and Multicultural Development, v. 33, n. 1, p. 3-11, 2012.

https://doi.org/10.1080/01434632.2011.638072

SPOLSKY, B. Language Policy. Cambridge: Cambridge University Press, 2004.

Recebido em: 19/04/2020.

Aceito em: 17/07/2020. 